\title{
Overexpression of TBX3 transcription factor as a potential diagnostic marker for breast cancer
}

\author{
SAEB ALIWAINI ${ }^{1}$, ABDEL MONEM LUBBAD $^{2}$, AHMED SHOURFA $^{3}$, \\ HOSAM A.A. HAMADA ${ }^{4}$, BASIM AYESH ${ }^{5}$, HUSAM EDDEEN M. ABU TAYEM ${ }^{1}$, AYMAN ABU MUSTAFA ${ }^{6}$, \\ FAYEK ABU ROUK ${ }^{3}$, MOEN M. REDWAN ${ }^{4}$ and MOHAMED AL-NAJJAR ${ }^{3}$ \\ ${ }^{1}$ Department of Biological Sciences and Biotechnology, Faculty of Sciences, Islamic University of Gaza; \\ ${ }^{2}$ Department of Pathology, Faculty of Medicine, Islamic University of Gaza, 108 Gaza; ${ }^{3}$ Department of Oncology, \\ European Gaza Hospital, 7049 Gaza; ${ }^{4}$ Department of Pathology, Alshefa Hospital, 1016 Gaza; ${ }^{5}$ Department of Laboratory \\ Medical Sciences, Alaqsa University, 4051 Gaza; ${ }^{6}$ Nursing Department, Palestine College of Nursing, 7049 Gaza, Palestine
}

Received July 3, 2018; Accepted October 26, 2018

DOI: $10.3892 / \mathrm{mco} .2018 .1761$

\begin{abstract}
The T-box 3 (TBX3) transcription factor has been shown to serve multiple roles in normal development. Recent findings have revealed that TBX3 is overexpressed in different types of carcinomas, including breast, cervical, ovarian, melanoma, pancreatic, lung, liver, bladder, head and neck. Therefore, the present study investigated the significance of TBX3 as a diagnostic marker of breast cancer. To achieve this aim, breast cancer samples and their adjacent normal tissues were collected from 51 breast cancer patients from the European Gaza hospital during 2015-2016. Sections from each sample were immune-stained by anti-TBX3 and suitable secondary and tertiary antibodies. TBX3 levels were evaluated in cancerous and normal samples. Clinicopathological data for each patient were documented. The correlation between TBX3 levels and the clinicopathological parameters were statistically tested. The results revealed that TBX3 is significantly overexpressed in breast cancer tissues when compared with normal tissues. Furthermore, TBX3 was mainly a cytoplasmic protein in normal and breast cancer tissues. Notably, TBX3 levels exhibited a sensitivity of $78.4 \%$, specificity of $79.6 \%$, accuracy of $79 \%$ and area under the curve of 0.791 $(0.700-0.882)$ at a cut-off value $=9$ as breast cancer marker. However, no significant associations were observed between TBX3 levels and other breast cancer markers including oestrogen receptor, progesterone receptor, human epidermal growth factor receptor 2, cancer antigen 15-3 and breast cancer stages. Altogether, these results suggested that TBX3 overexpression may be a potential biomarker for breast cancer.
\end{abstract}

Correspondence to: Dr Saeb Aliwaini, Department of Biological Sciences and Biotechnology, Faculty of Sciences, Islamic University of Gaza, Room 525, Faculty of Science Building, Rimal Street, 108 Gaza, Palestine

E-mail: saib.iwini@gmail.com

Key words: T-box 3 transcription factor, breast cancer diagnosis

\section{Introduction}

Breast cancer is the most common malignancy worldwide and it is estimated that one out of eight women will develop breast cancer in their life time $(1,2)$. Unfortunately, in spite of the enormous efforts invested to treat breast cancer there has been limited success because many patients still diagnosed too late and several types of breast tumours develop resistance to the current chemotherapies $(3,4)$. There is therefore a need to develop more effective diagnostic and therapeutic approaches to treat this devastating disease. One important strategy to fight breast cancer is to identify more effective diagnostic targets for this disease.

The T-box family of transcription factors are important developmental regulators and have been shown to contribute to several human syndromes $(5,6)$. In addition to their key role in development, extensive investigations suggested that overexpression of some T-box factors, including TBX2 and TBX3 may drive cancer (6-12). Both transcription factors are upregulated in a number of cancers including melanoma $(13,14)$ and breast cancer $(15,16)$ where it was shown to be required for tumour formation and cell migration (6,17-19). Importantly, knocking down TBX2 and TBX3 was shown to reverse key features of the melanoma and breast cancer phenotype suggesting that it might be a useful target in the development of novel anti-cancer drugs to treat these cancers $(12,20)$. Previous study suggested TBX3 as a potential biomarker for early stages of breast cancer (21). The same study showed that malignant cells of primary breast cancer tissue express higher TBX3 levels than normal breast epithelial cells in both nucleus and cytoplasm. The elevated cytoplasmic TBX3 protein level suggests that TBX3 might leak into the cytoplasm and subsequently enter the blood stream from the tumor tissue. This was further supported by another interested study which showed that TBX3 can be used as component of multiparameter monitoring of ovarian and breast cancer at the early stages (22). All together these data highlighted the importance of TBX3 as a potential biomarker for breast cancer. In this regard, the current study aimed to test whether TBX3 is overexpressed in different stages of breast cancer 
tissues and to test its significance as a diagnostic biomarker to identify tumor cells from normal cells in breast tissue. Our study demonstrated that TBX3 is overexpressed in different stages of breast cancer tissues and it might be reliable marker to distinguish between breast cancer cells and normal cells in the same tissue. This is significant to facilitate and to improve breast cancer diagnosis.

\section{Materials and methods}

Breast cancer samples. This study has a retrospective design and the protocol was approved by the Helsinki Committee of the Palestinian Health Research Council under approval number (PHRC/HC/93/16). All pathologically verified breast cancer cases admitted to the European Gaza Hospital and subjected to mastectomy during $2016(n=51)$ were included in this study. For each patient, two paraffin-embedded tissue blocks containing cancer and non-cancer tissues were included. Important to note that after the histopathological examinations, 7 samples of the non-cancer tissues were found to be invaded by cancer cells and they were excluded from the non-cancer tissues. Therefore, the total number of samples in this study was 51 cancer tissues and 44 non-cancer tissues of the same patients and no samples of healthy volunteers were included.

None of the patients received neo-adjuvant chemotherapy. The clinical and pathological features of the population-based breast cancer tissue samples are shown in Table I.

Immunohistochemistry. Tissues embedded in a paraffin blocks were cut into $4 \mu \mathrm{m}$ thick sections. The sections were deparaffinized with a xylene substitute and rehydrated using decreasing concentrations of ethyl alcohol. For retrieval, hydration and washing triology (Cell Marque ${ }^{\mathrm{TM}}$; Merck KGaA, Darmstadt, Germany) was used and for blocking hydrogen peroxide was used. The sections were incubated with a 1:150 dilution of rabbit anti-human TBX3 (ab89220, Abcam, Cambridge, UK). Primary antibody detected by HRP HiDef 2-Step Polymer Detection ${ }^{\mathrm{TM}}$ kit (954D, Cell Marque ${ }^{\mathrm{TM}}$ ). For all reactions, the DAB chromogen kit (957D, Cell Marque ${ }^{\mathrm{TM}}$ ) was used. Finally all sections were counterstained with haematoxylin, dehydrated and mounted. Negative controls were treated identically, except of the primary antibody. The slides were examined using an iScan Coreo Digital Microscope (Version 3.3, Ventana Medical Systems, Inc., Tucson, AZ, USA) (21). Notably, due the heterogeneity of the tumour tissues it's not possible to separately extract proteins from cancer cells and normal cells. Therefore immunohistochemistry was used to evaluate TBX3 level in both types of cells and not western blot analysis.

Scoring method for TBX3 level. The immunostained slides were scored for TBX3 level by two independent pathologists, both of them are not involved in any step of immunohistochemistry protocol preparations and without any information of clinical patient's reports. The tissue slides were scored using Leake et al (23) scoring system with some modifications. Briefly, 20 normal cells (in the normal sections) or 20 tumor cells (in the tumor sections) were randomly chosen and scored. Both nuclear and cytoplasmic staining were considered. Two scoring systems were used: i) Staining intensity based system; and ii) proportion of stained cells based system. For proportion staining score, both nuclear and cytoplasmic proportion were respectively classified into six grades (0-5). The sum of these two scores 0 to 8 was given to describe the nuclear and cytoplasmic staining separately $(23,24)$. By combining these two cytoplasmic and nuclear scores, the total tbx 3 level score was 0 to 16 . Suggested scoring system is summarized in Table II.

Our modifications include combining the cytoplasmic and nuclear grades to measurer the total TBX3 level in the cells. The TBX3 level scores obtained ranged from 0 to 16 , and divided into five groups: (0-1) Negative staining, (2-6) weak positive staining, (7-11) moderate positive staining and (12-16) strong positive staining. Applied scoring system is summarized in (Table II).

Statistical analysis. TBX3 expression in normal and breast cancer tissue was analyzed using standard statistical methods. All statistical analyses were performed using SPSS software package version 22.0 (IBM Corp., Armonk, NY, USA). Percentages and frequencies were used to represent most personal information variables. Then the mean, standard deviation, Median, Range, Maximum and Minimum were calculated for variables; t-test was used to compare between TBX3 expression in tumor and normal tissues.

Correlations were performed by Spearman's rank correlations test to determine the relation between TBX3 level and clinicopathological features including: Age, tumor size, lymph node size, lymph node metastasis and common breast cancer biomarkers including: CA15-3, ER, PR and HER2. This test is based on the study of the relationship between two variables.

Mann-Whitney U-test (MW) was used to study the relationships between TBX3 expression and clinicopathological features including: IDC and ILC breast cancer types, and also non-metastatic and metastatic breast cancer. For example, this analysis was used to compare between the total TBX3 level in invasive lobular carcinoma (ILC) and in invasive ductal breast cancer (IDC). Also to compare between total TBX3 level of M0 and M1 for tumor metastasis. Kruskal-Wallis H-test (KW) was applied for statically comparison between three study groups or more. This assay was used to study the relationships between TBX3 expression and clinicopathological features include breast cancer stages (I, II, III and IV) and histological grades (1,2 and 3$)$. $\mathrm{P}<0.05$ was considered to indicate a statistically significant difference.

Diagnostic accuracy of TBX3 levels were detected by receiver operating characteristic curve (ROC). Cut-off value and area under a ROC curve (AUC) were used to determine the significance of nuclear, cytoplasmic and total TBX3 levels as tumor marker. The values of the maximum sum of sensitivity and specificity were considered as the optimal cut off values. In addition, sensitivity, specificity, accuracy, positive predictive value (PPV) and negative predictive value (NPV) were calculated.

\section{Results}

TBX3 is overexpressed in different stages breast cancer tissues. Previous studies showed that TBX3 is overexpressed in a subset of breast cancer cell lines (25) and primary breast cancer tissues (21). 
Table I. Clinical and pathological characteristics of patients.

\begin{tabular}{ll}
\hline Characteristic & No. of patients, n (\%) \\
\hline
\end{tabular}

\begin{tabular}{ll}
\hline Total & $51(100)$ \\
Age (year)
\end{tabular}

Age (year)

$$
\leq 50
$$

$>50$

Tumour size $(\mathrm{cm})$

$$
\begin{aligned}
& \leq 2 \\
& 2-5
\end{aligned}
$$

Unknown

$1(2)$

Lymph node metastasis

$$
\begin{aligned}
& 0 \\
& 1-3 \\
& 4-9 \\
& \geq 10
\end{aligned}
$$

Cancer metastasis

$$
\text { M0 }
$$

M1

Unknown

$9(18)$
$1(2)$

Histological type

$$
\begin{aligned}
& \text { IDC } \\
& \text { ILC } \\
& \text { DCIS }
\end{aligned}
$$

ER scoring

0

1

2

3

\section{Unknown}

PR scoring

$$
0
$$$$
1
$$$$
2
$$$$
3
$$

Unknown

10 (19.6)

9 (17.6)

7 (13.7)

5 (9.8)

20 (39.2)

10 (19.6)

10 (19.6)

4 (7.8)

7 (13.7)

20 (39.2)

HER2 scoring

0

Unknown

CA15-3 antigen $(\mathrm{U} / \mathrm{ml})$

$$
\begin{array}{lc}
\leq 30 & 12(23.5) \\
>30 & 4(7.8) \\
\text { Unknown } & 35(68.6)
\end{array}
$$

Table II. Scoring system for nuclear staining, cytoplasmic staining and total score.

A, Scores for nuclear staining

\begin{tabular}{ll}
\hline Proportion score & \multicolumn{1}{c}{ Intensity score } \\
\hline $0=$ No staining & $0=$ No staining \\
$1=<1 \%$ staining & $1=$ Weak staining \\
$2=1-10 \%$ staining & $2=$ Moderate staining \\
$3=11-33 \%$ staining & $3=$ Strong staining \\
$4=34-66 \%$ staining & - \\
$5=67-100 \%$ staining & - \\
Rules & Adding the two scores together \\
& gives a nuclear score of $(0-8)$. \\
\hline
\end{tabular}

B, Scores for cytoplasmic staining

\begin{tabular}{ll}
\hline Proportion score & \multicolumn{1}{c}{ Intensity score } \\
\hline $0=$ No staining & $0=$ No staining \\
$1=<1 \%$ staining & $1=$ Weak staining \\
$2=1-10 \%$ staining & $2=$ Moderate staining \\
$3=11-33 \%$ staining & $3=$ Strong staining \\
$4=34-66 \%$ staining & - \\
$5=67-100 \%$ staining & -
\end{tabular}

Rules

Adding the two scores together gives a cytoplasmic score (0-8).

C, Total score

\begin{tabular}{ll}
\hline Total score & \multicolumn{1}{c}{ Staining levels } \\
\hline $0-1$ & Negative staining \\
$2-6$ & Weak positive staining \\
$7-11$ & Moderate positive staining \\
$12-16$ & Strong positive staining \\
Rules & Adding the nuclear score $(0-8)$ \\
& and cytoplasmic score $(0-8)$ \\
& together gives the total protein \\
& level of cell $(0-16)$.
\end{tabular}

In the current study, we tested whether TBX3 is overexpressed in different stages and types of breast cancer tissues. TBX3 protein level could be evaluated in breast cancer tissues by different techniques such as immunohistochemistry and western blot analysis. However, tumor tissues usually include mixtures of both normal and malignant cells, and therefore, only a subpopulation of tumor cells represent the nature of cancer cells. To overcome this problem, we performed immunohistochemistry analysis to evaluate TBX3 protein level in breast cancer cells included in the tumor tissues in comparison to normal cells out of the tumortissues. Tumor and normal sections were stained and scored as described in the materials and methods section $(21,23,26)$. Results showed that TBX3 protein is overexpressed in tumour tissues compared with normal tissues among breast cancer patients (Fig. 1). The 
Table III. Expression level of TBX3 in normal and tumour tissues.

\begin{tabular}{lccccrr}
\hline & & \multicolumn{4}{c}{ TBX3 expression (n) } & \\
\cline { 3 - 6 } & Total no. & Negative $(\%)$ & Weak $(\%)$ & Moderate $(\%)$ & Strong (\%) & P-value \\
\hline Normal & 44 & $2(4.54)$ & $11(25)$ & $26(59.1)$ & $5(11.36)$ & $<0.001$ \\
Tumour & 44 & $0(0)$ & $2(4.54)$ & $21(47.73)$ & $21(47.73)$ & $<0.001$
\end{tabular}

A total number of 44 cancer tissue samples versus 44 non cancer tissues were used in this test. This number was used as the other 7 samples did not have non-cancerous tissues due to the large size of the tumor. TBX3, T-box 3 .
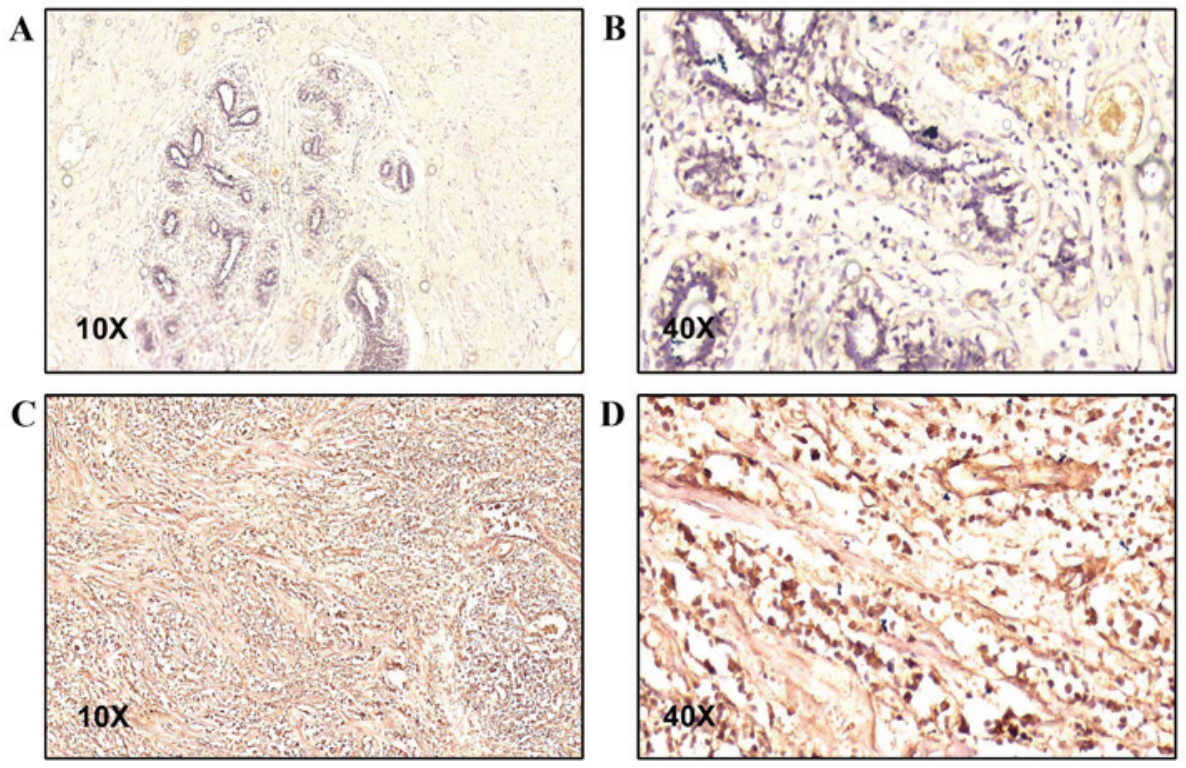

Figure 1. TBX3 levels in normal and cancerous tissues from the human breast. Normal human breast epithelial tissues had low TBX3 Levels at (A) magnification, $\mathrm{x} 10$ and (B) x40. Breast cancer tissues at (C) magnification, x10 and (D) at x40 exhibited high levels of TBX3. TBX3, T-box 3.
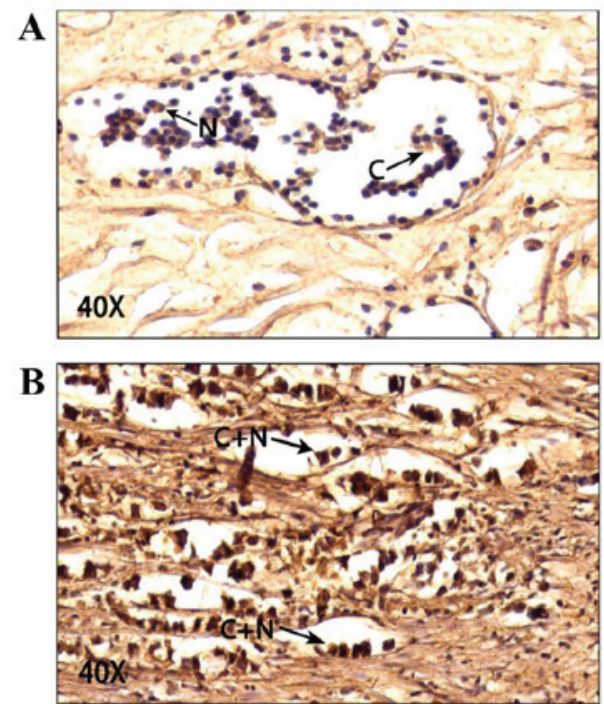

Figure 2. Cytoplasmic and nuclear TBX3 protein in normal and cancerous breast tissues. (A) Representative photograph of normal human breast tissues expressing low TBX3 protein levels, mainly in the cytoplasm and nucleus (magnification, $\mathrm{x} 40$ ). (B) Representative photograph of breast cancer tissues exhibited higher levels of cytoplasmic and nuclear TBX3 protein when compared with normal tissues (magnification, $\mathrm{x} 40$ ). The tumour and norma breast cells exhibited TBX3 overexpression in the cytoplasm when compared with the nucleus. TBX3, T-box 3 . mean of TBX3 level in tumour tissues is $10.9 \pm 2.5$ and in normal tissues is $6.7 \pm 3.8(\mathrm{P}<0.001)$. Importantly, 21 patients $(47.73 \%)$ showed strong positive TBX3 staining in tumour tissue and only 5 (11.36\%) of normal tissues showed similar levels of TBX3. While only two tumour samples (4.54\%) showed weak TBX3 level, 11 samples $(25 \%)$ of normal tissues showed weak TBX3 level. Moreover, no tumour tissues showed completely negative TBX3 level but 2 (4.54\%) normal tissues showed negative TBX3 stain. The expression level of TBX3 in normal and tumour tissue are summarized in Table III. Importantly, our results revealed that TBX3 is mainly cytoplasmic in both normal and breast cancer tissues (Fig. 2). According to our scoring system, the mean of cytoplasmic TBX3 level in normal cells is 5.3 \pm 1.6 compared with $2.6 \pm 2$ in the nucleus and this difference is significant with $\mathrm{P}<0.001$ (Table IV). Similarly, the mean of cytoplasmic TBX3 level in tumour cells is $6.7 \pm 1.4$ compared with $4.2 \pm 2.2$ in the nucleus and this difference is also significant $(\mathrm{P}<0.001)$. These results show that TBX3 is significantly overexpressed in breast cancer cells.

TBX3 is a promising diagnostic marker for breast cancer. To explore the significance of TBX3 as a diagnostic marker of breast cancer, we analysed the obtained data using the ROC curve and AUC. Youden's index was used to determine the cut-off value 
Table IV. Cytoplasmic and nuclear Tbx3 levels in normal and tumour tissues.

\begin{tabular}{|c|c|c|c|c|}
\hline Tbx3 proteins & Normal cells $(n=44)$ & Tumour cells $(n=51)$ & $\mathrm{t}$ & P-value \\
\hline Cytoplasmic level, Mean \pm SD (Min-Max) & $5.3 \pm 1.6(0-8)$ & $6.7 \pm 1.4(3-8)$ & 4.851 & $<0.001$ \\
\hline Nuclear level, Mean \pm SD (Min-Max) & $2.6 \pm 2(0-6)$ & $4.2 \pm 2.2(0-8)$ & 3.731 & $<0.001$ \\
\hline
\end{tabular}

$\mathrm{SD}$, standard deviation; Tbx3, T-box 3 .

Table V. Youden index cut-off values, sensitivity, specificity, PPV, NPV and AUC of TBX3 biomarker for breast cancer diagnoses .

\begin{tabular}{|c|c|c|c|c|c|c|c|c|c|c|}
\hline Biomarker & $\begin{array}{l}\text { Cut-off } \\
\text { point }\end{array}$ & $\begin{array}{l}\text { Tumor } \\
\text { tissues } \\
(n=51)\end{array}$ & $\begin{array}{c}\text { Normal } \\
\text { Tissues } \\
(n=44)\end{array}$ & $\begin{array}{c}\text { Sensitivity } \\
(\%)\end{array}$ & $\begin{array}{c}\text { Specificity } \\
(\%)\end{array}$ & $\begin{array}{c}\text { Accuracy } \\
(\%)\end{array}$ & $\begin{array}{l}\mathrm{PPV} \\
(\%)\end{array}$ & $\begin{array}{l}\text { NPV } \\
(\%)\end{array}$ & $\begin{array}{c}\text { AUC } \\
(95 \% \mathrm{CI})\end{array}$ & P-value \\
\hline Cytoplasmic & $\leq 6$ & 15 & 38 & 70.6 & 86.4 & 77.9 & 85.7 & 71.7 & 0.789 & $<0.001$ \\
\hline TBX3 (0-8) & $>6$ & 36 & 6 & & & & & & $(0.695-0.882)$ & \\
\hline Nuclear & $\leq 4$ & 28 & 39 & 45.1 & 88.6 & 65.3 & 82.1 & 58.2 & 0.701 & 0.001 \\
\hline TBX3 (0-8) & $>4$ & 23 & 5 & & & & & & $(0.597-0.805)$ & \\
\hline Total TBX3 & $\leq 9$ & 11 & 34 & 78.4 & 79.6 & 79.0 & 80.0 & 78.0 & 0.791 & $<0.001$ \\
\hline level (0-16) & $>9$ & 40 & 10 & & & & & & $(0.700-0.882)$ & \\
\hline
\end{tabular}

PPV, positive predictive value; NPV, negative predictive value; AUC, area under the curve; $95 \%$ CI, 95\% confidence interval; TBX3, T-box 3.

Table VI. Correlations between TBX3 level and clinicopathological parameters among study population.

\begin{tabular}{lcc}
\hline & \multicolumn{2}{c}{$\begin{array}{c}\text { Correlation with TBX3 level } \\
\text { in tumor cells }\end{array}$} \\
\cline { 2 - 3 } Parameters & $\mathrm{R}$ & P-value \\
\hline Age (years) & -0.130 & 0.364 \\
Tumour size (cm) & -0.038 & 0.791 \\
LN metastasis (\%) & 0.160 & 0.263 \\
LN size (cm) & -0.072 & 0.638 \\
ER & -0.004 & 0.982 \\
PR & 0.016 & 0.930 \\
HER2 & 0.092 & 0.622 \\
CA15-3 & -0.115 & 0.670 \\
\hline
\end{tabular}

ER, estrogen-receptor; PR, progesterone receptor; HER2, human epidermal growth factor 2; CA15-3, cancer antigen 15-3; LN, lymph node; R, Spearman's rank correlation coefficient (Nonparametric).

for TBX3 level in tumour tissues compared to normal tissues. These methods were used by several studies to show the diagnostic value of tumour makers including carcinoembryonic antigen (CEA), cancer antigen 19-9 (CA19-9), cancer antigen 125 (CA125), CA15-3 and tissue polypeptide-specific antigen (TPS) in metastatic breast cancer (27-30).

The results showed that TBX3 protein is statistically significant diagnostic marker for breast cancer $(\mathrm{P}<0.001)$. The cut-off value for TBX3 level was 9 of a total score 16 . The AUC was $0.791(\mathrm{P}<0.001)$, sensitivity and specificity were 78.4 and $79.6 \%$ respectively. PPV was $80 \%$, NPV was $78 \%$, and accuracy of TBX3 as diagnostic breast cancer marker was 79\%. The cut-off value for cytoplasmic TBX3 was 6 of a total score 8 . The AUC was $0.798(\mathrm{P}<0.001)$, sensitivity was $70.6 \%$, specificity was $86.4 \%$, PPV was 85.7 , NPV was 71.7 , and accuracy was $77.9 \%$. In addition to the cytoplasmic TBX3, the cut-off value of nuclear TBX3 was 4 of a total score 8 , the AUC was $0.701(\mathrm{P}=0.001)$, sensitivity was $45.1 \%$, specificity was $88.6 \%$, PPV was 82.1 , NPV was 58.2 , and accuracy was $65.3 \%$ (Table V and Fig. 3). Furthermore, cytoplasmic TBX3 has higher accuracy than nuclear TBX3 whereas nuclear TBX3 has higher specificity than cytoplasmic TBX3. However, in comparison to the cytoplasmic and nuclear TBX3, total TBX3 level showed the best diagnosability for breast cancer with the highest sensitivity of $78.4 \%$, highest AUC of 0.791 $(0.700-0.882)$ at cut-off value $=9$. Which means that TBX3 staining assay has the ability to distinguish between normal and tumour tissues. Together, these findings suggest total TBX3 level as a potential diagnostic marker for breast cancer.

Associations between clinicopathological parameters and $T B X 3$ expression. Our results indicate that there are no significant correlations between TBX3 protein level and clinicopathological parameters in breast cancer at confidence level 0.05. These clinicopathological parameters include age, anatomic stage, cancer type, histopathological grade, tumour size, lymph node size, lymph node metastasis and tumour metastasis. Similarly, no significant correlation between TBX3 level and ER, PR, HER2 and CA15-3 levels as tested by Spearman rank correlation, 
Table VII. Differences of TBX3 levels among tumour stages in breast cancer patients.

\begin{tabular}{|c|c|c|c|c|c|}
\hline \multirow[b]{2}{*}{ Variable } & \multirow[b]{2}{*}{ Total n } & \multicolumn{2}{|c|}{ Total TBX3 (0-16) } & \multicolumn{2}{|c|}{ Statistical analysis } \\
\hline & & Median & IQR (25th-75th) & $\mathrm{MW} / \mathrm{KW}$ & P-value \\
\hline Type of tumour & & & & 203.017 & 0.567 \\
\hline ILC & 12 & 7.5 & $0-13$ & & \\
\hline IDC & 38 & 7 & $0-12$ & & \\
\hline Tumour metastasis & & & & 178.525 & 0.882 \\
\hline M0 & 41 & 11 & $10-13$ & & \\
\hline M1 & 9 & 11 & $9-13$ & & \\
\hline Histopathological grade & & & & 0.215 & 0.898 \\
\hline Grade 1 & 3 & 9 & $0-11$ & & \\
\hline Grade 2 & 31 & 7 & $0-12$ & & \\
\hline Grade 3 & 2 & 6 & $0-12$ & & \\
\hline Stage of cancer & & & & 7.011 & 0.072 \\
\hline I & 2 & 14 & $14-14$ & & \\
\hline II & 19 & 10 & $8-12$ & & \\
\hline III & 20 & 12 & $10-13$ & & \\
\hline IV & 9 & 11 & $9-13$ & & \\
\hline
\end{tabular}

MW was performed for analysing the type of tumour and tumour metastasis; KW was performed for histopathological grade and stage of cancer. ILC, invasive lobular carcinoma; IDC, invasive ductal breast cancer; M0, no metastasis; M1, metastasis; MW, Mann-Whitney (U) test; $\mathrm{KW}$, Kruskal-Wallis $(\mathrm{H})$ test; IQR, interquartile range.

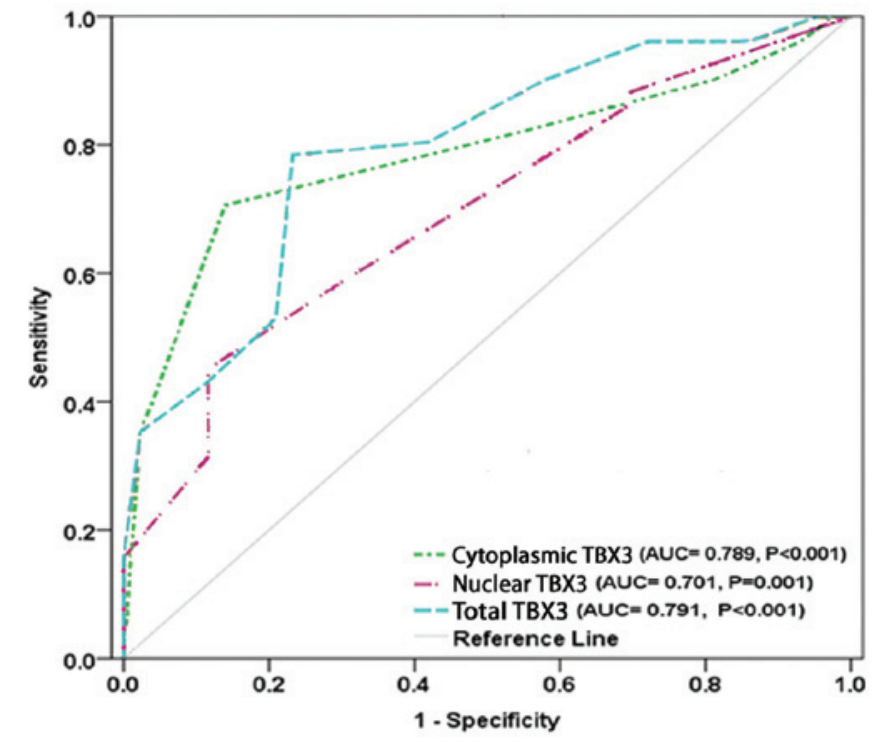

Figure 3. Receiver operating characteristic curves for TBX3 breast cancer diagnoses biomarkers. TBX3, T-box 3; AUC, area under the curve.

KW(H) test and Mann-Whitney (U) test (Tables VI and VII). Therefore, these findings suggest TBX3 overexpression as biomarker for human breast cancer regardless of age, stage, grade, metastasis, non-metastasis, and breast cancer type.

\section{Discussion}

TBX3 is a member of T-box transcription factors family that plays critical roles in development and oncogenic process (31). Many evidence point out a functional linkage between T-box genes, cellular differentiation/proliferation, and tumorigenesis, especially breast cancers (32). Also, it has been involved in a widespread range of carcinomas like, ovarian, cervical, pancreatic, bladder, liver and melanoma.

The present study is a cross-sectional and hospital-based study included 51 breast cancer patient samples. Tissues were collected by mastectomy from breast cancer patients and embedded in paraffin blocks. Usually, in breast cancer samples there are cancer cells and normal cells and generally the normal cells are located in the edge of the sample, therefore the level of TBX3 was estimated by immunohistochemistry analysis in both normal and cancer cells. Histologically normal tissue adjacent to the tumour (NAT) is commonly used as a control in cancer studies. However, little is known about the transcriptomic profile of NAT, how it is influenced by the tumour, and how the profile compares with non-tumour-bearing tissues (33). Still, the study of tumour biology, irrespective of approach, requires controls. Using normal adjacent tissue as this control has many advantages, such as the relative ease of access and the control for variability between individuals and anatomic sites. Our results showed that TBX3 is significantly overexpressed in breast cancer tissues. This is in agreement with several previous in vitro and in vivo studies. For example, an early study tested several breast cancer cell lines showed that TBX3 is overexpressed in many breast cancer cell lines, where it plays a role in inhibition of the senescence (25). A study by Yarosh et al (21) suggested that TBX3 might be overexpressed in patients breast cancer tissues. This study was carried out in the United States and showed that TBX3 is significantly overexpressed in 42 breast cancer tissues in comparison to normal tissues. Importantly, Yarosh et al tested breast cancer samples of early stages but the current study included all stages of breast cancer patients. Additionally, while the previous study 
showed that TBX3 is mainly cytoplasmic in breast cancer cells only, we showed that TBX3 is mainly cytoplasmic protein in both normal and breast cancer tissues. Significantly, the current study provides more statistical analysis to show the importance of TBX3 as a marker of breast cancer cells. Another recent study found that TBX3 protein has different levels and localizations in the different stages of cell cycle (1). The study showed that TBX3 levels increases during G1 and peaks in S-phase. While the protein is both nuclear and cytoplasmic in G1 and G2, it is predominantly nuclear in S-phase cells. These results provide evidence that TBX3 levels and localization is regulated during the cell cycle and that it may have a more important role in S-phase. Other studies showed that TBX3 stabilization and subcellular localization depend on its phosphorylation at specific sites (14). All together, these studies and our current findings show that TBX3 is overexpressed in breast cancer tissues where it could be used as diagnostic or prognostic marker. Furthermore, it provides evidence that TBX3 localizes differently depending on its role and the cell cycle phase (34-36). However, due to the small number of our patients, the results of ROC analysis need validation using an independent breast cancer cohort. Furthermore, in our study, we didn't compare between TBX3 levels in cancer patients vs. healthy subjects but we showed that TBX3 might be suitable to distinguish between tumor cells and normal cells in breast cancer patients. Finally, the current study as well as different previous studies $(21,23,26)$ didn't use specific markers for specific organelles and alternatively pathologists depend on the morphological features of the organelles to identify them, which might be considered as another a limitation of this technique.

\section{Acknowledgements}

The authors would like to acknowledge the Palestinian Ministry of Health for their assistance in sample collection.

\section{Funding}

The present study was supported by the Qatar Charity under the Ibhath project for research grants, which is funded by the Cooperation Council for the Arab States of the Gulf through the Islamic Development Bank.

\section{Availability of data and materials}

All data generated or analyzed during this study are included in this published article.

\section{Authors' contributions}

SA designed the study, supervised the experimental procedures such as section preparations and staining, performed the statistical analyses and was a major contributor in writing the manuscript. AL, HH and FR diagnosed the breast cancer sections and evaluated TBX3 levels in the cancerous and normal sections. AS was the oncologist who diagnosed and treated all of the patients, and AS also assisted with writing the paper. AM performed the statistical analyses. HT collected and prepared the samples and contributed to writing the paper. MR and MN performed sectioning and staining the different tissues. BA designed the study and wrote the paper with SA.

\section{Ethics approval and consent to participate}

The present retrospective study was approved by the Helsinki Committee of the Palestinian Health Research Council (approval no. PHRC/HC/93/16). Each patient provided written informed consent, which was conducted with the kind assistance of the Palestinian Ministry of Health.

\section{Patient consent for publication}

Not applicable.

\section{Competing interests}

The authors declare that there are no competing interests.

\section{References}

1. Willmer T, Peres J, Mowla S, Abrahams A and Prince S: The T-Box factor TBX3 is important in S-phase and is regulated by c-Myc and cyclin A-CDK2. Cell Cycle 14: 3173-3183, 2015.

2. Cheng HD, Lui YM and Freimanis RI: A novel approach to microcalcification detection using fuzzy logic technique. IEEE Trans Med Imaging 17: 442-450, 1998.

3. American Cancer Society: Cancer Treatment and Survivorship Facts and Figures 2012-2013. https://www.cancer.org/content/ dam/cancer-org/research/cancer-facts-and-statistics/cancertreatment-and-surviorship-facts-and-figures/cancer-treatmentand-survivorship-facts-and-figures-2012-2013.pdf. Accessed January 1, 2012.

4. Ashkenazi A: Targeting the extrinsic apoptosis pathway in cancer. Cytokine Growth Factor Rev 19: 325-331, 2008.

5. Naiche LA, Harrelson Z, Kelly RG and Papaioannou VE: T-box genes in vertebrate development. Annu Rev Genet 39: 219-239, 2005.

6. Peres J and Prince S: The T-box transcription factor, TBX3, is sufficient to promote melanoma formation and invasion. Mol Cancer 12: 117, 2013.

7. Bilican B and Goding CR: Cell cycle regulation of the T-box transcription factor tbx2. Exp Cell Res 312: 2358-2366, 2006

8. Burgucu D, Guney K, Sahinturk D, Ozbudak IH, Ozel D, Ozbilim G and Yavuzer U: Tbx3 represses PTEN and is over-expressed in head and neck squamous cell carcinoma. BMC Cancer 12: 481, 2012.

9. Demay F, Bilican B, Rodriguez M, Carreira S, Pontecorvi M, Ling Y and Goding CR: T-box factors: Targeting to chromatin and interaction with the histone H3 N-terminal tail. Pigment Cell Res 20: 279-287, 2007.

10. Hoogaars WM, Barnett P, Rodriguez M, Clout DE, Moorman AF Goding CR and Christoffels VM: TBX3 and its splice variant TBX3 + exon 2 a are functionally similar. Pigment Cell Melanoma Res 21: 379-387, 2008.

11. Humtsoe JO, Koya E, Pham E, Aramoto T, Zuo J, Ishikawa T and Kramer RH: Transcriptional profiling identifies upregulated genes following induction of epithelial-mesenchymal transition in squamous carcinoma cells. Exp Cell Res 318: 379-390, 2012.

12. Peres J, Davis E, Mowla S, Bennett DC, Li JA, Wansleben S and Prince S: The highly homologous T-Box transcription factors, TBX2 and TBX3, have distinct roles in the oncogenic process. Genes Cancer 1: 272-282, 2010.

13. Hoek K, Rimm DL, Williams KR, Zhao H, Ariyan S, Lin A, Kluger HM, Berger AJ, Cheng E, Trombetta ES, et al: Expression profiling reveals novel pathways in the transformation of melanocytes to melanomas. Cancer Res 64: 5270-5282, 2004.

14. Peres J, Mowla S and Prince S: The T-box transcription factor, TBX3, is a key substrate of AKT3 in melanomagenesis. Oncotarget 6: 1821-1833, 2015.

15. Douglas NC and Papaioannou VE: The T-box transcription factors TBX2 and TBX3 in mammary gland development and breast cancer. J Mammary Gland Biol Neoplasia 18: 143-147, 2013. 
16. Wu G, Sinclair C, Hinson S, Ingle JN, Roche PC and Couch FJ: Structural analysis of the 17q22-23 amplicon identifies several independent targets of amplification in breast cancer cell lines and tumors. Cancer Res 61: 4951-4955, 2001.

17. Jacobs JJ, Keblusek P, Robanus-Maandag E, Kristel P Lingbeek M, Nederlof PM, van Welsem T, van de Vijver MJ, Koh EY, Daley GQ, et al: Senescence bypass screen identifies TBX2, which represses Cdkn2a (p19 (ARF)) and is amplified in a subset of human breast cancers. Nat Genet 26: 291-299, 2000.

18. Redmond KL, Crawford NT, Farmer H, D'Costa ZC, O'Brien GJ, Buckley NE, Kennedy RD, Johnston PG, Harkin DP and Mullan PB: T-box 2 represses NDRG1 through an EGR1-dependent mechanism to drive the proliferation of breast cancer cells. Oncogene 29: 3252-3262, 2010.

19. Yu J, Ma X, Cheung KF, Li X, Tian L, Wang S, Wu CW, Wu WK, He M, Wang M, et al: Epigenetic inactivation of T-box transcription factor 5, a novel tumor suppressor gene, is associated with colon cancer. Oncogene 29: 6464-6474, 2010.

20. Wansleben S, Davis E, Peres J and Prince S: A novel role for the anti-senescence factor TBX2 in DNA repair and cisplatin resistance. Cell Death Dis 4: e846, 2013.

21. Yarosh W, Barrientos T, Esmailpour T, Lin L, Carpenter PM, Osann K, Anton-Culver $\mathrm{H}$ and Huang T: TBX3 is overexpressed in breast cancer and represses p14 ARF by interacting with histone deacetylases. Cancer Res 68: 693-699, 2008.

22. Lomnytska M, Dubrovska A, Hellman U, Volodko N and Souchelnytskyi S: Increased expression of cSHMT, Tbx3 and utrophin in plasma of ovarian and breast cancer patients. Int J Cancer 118: 412-421, 2006.

23. Leake R, Barnes D, Pinder S, Ellis I, Anderson L, Anderson T, Adamson R, Rhodes T, Miller K and Walker R: Immunohistochemical detection of steroid receptors in breast cancer: A working protocol. UK Receptor Group, UK NEQAS, The Scottish Breast Cancer Pathology Group, and The Receptor and Biomarker Study Group of the EORTC. J Clin Pathol 53: 634-635, 2000.

24. Sasaki T, Ryo A, Uemura H, Ishiguro H, Inayama Y, Yamanaka S, Kubota Y, Nagashima Y, Harada M and Aoki I: An immunohistochemical scoring system of prolyl isomerase Pin1 for predicting relapse of prostate carcinoma after radical prostatectomy. Pathol Res Pract 202: 357-364, 2006.

25. Fan W, Huang X, Chen C, Gray J and Huang T: TBX3 and its isoform $\mathrm{TBX} 3+2 \mathrm{a}$ are functionally distinctive in inhibition of senescence and are overexpressed in a subset of breast cancer cell lines. Cancer Res 64: 5132-5139, 2004.
26. Sasaki K, Bastacky SI, Zynger DL and Parwani AV: Use of immunohistochemical markers to confirm the presence of vas deferens in vasectomy specimens. Am J Clin Pathol 132: 893-898, 2009.

27. Li X, Gao H, Chen Z, Zhang L, Zhu X, Wang S and Peng W: Diagnosis of breast cancer based on microcalcifications using grating-based phase contrast CT. Eur Radiol 28: 3742-3750, 2018.

28. Wu SG, He ZY, Zhou J, Sun JY, Li FY, Lin Q, Guo L and Lin HX Serum levels of CEA and CA15-3 in different molecular subtypes and prognostic value in Chinese breast cancer. Breast 23: 88-93, 2014.

29. Di Gioia D, Blankenburg I, Nagel D, Heinemann V and Stieber P: Tumor markers in the early detection of tumor recurrence in breast cancer patients: CA 125, CYFRA 21-1, HER2 shed antigen, LDH and CRP in combination with CEA and CA 15-3. Clin Chim Acta 461: 1-7, 2016.

30. Wang W, Xu X, Tian B, Wang Y, Du L, Sun T, Shi Y, Zhao X and Jing J: The diagnostic value of serum tumor markers CEA, CA19-9, CA125, CA15-3, and TPS in metastatic breast cancer. Clin Chim Acta 470: 51-55, 2017.

31. Willmer T, Hare S, Peres J and Prince S: The T-box transcription factor TBX 3 drives proliferation by direct repression of the p21(WAF1) cyclin-dependent kinase inhibitor. Cell Div 11: 6 , 2016.

32. Horton AC, Mahadevan NR, Minguillon C, Osoegawa K, Rokhsar DS, Ruvinsky I, de Jong PJ,Logan MP and Gibson-Brown JJ: Conservation of linkage and evolution of developmental function within the Tbx2/3/4/5 subfamily of T-box genes: Implications for the origin of vertebrate limbs. Dev Genes Evol 218: 613-628, 2008.

33. Aran D, Camarda R, Odegaard J, Paik H, Oskotsky B, Krings G, Goga A, Sirota M and Butte AJ: Comprehensive analysis of normal adjacent to tumor transcriptomes. Nat Commun 8: 1077, 2017.

34. Kunasegaran K, Ho V, Chang TH, De Silva D, Bakker ML, Christoffels VM and Pietersen AM: Transcriptional repressor Tbx 3 is required for the hormone-sensing cell lineage in mammary epithelium. PLoS One 9: e110191, 2014.

35. Sunwoo $\mathrm{HH}$ and Suresh MR: Cancer markers. In The Immunoassay. Handbook. Vol 1. 4th edition. Elsevier Ltd., Oxford, pp673-693, 2013.

36. Willmer T, Cooper A, Peres J, Omar R and Prince S: The T-Box transcription factor 3 in development and cancer. Biosci Trends 11: 254-266, 2017. 